\title{
PHYSIOLOGY OF MUSCLE
}

\begin{abstract}
$\mathrm{T}$ HE Medical Department of the British Council has once more been able to persuade a group of active and distinguished scientists to leave their benches and spend time on summarizing and interpreting recent progress in a field of active researchthis time, the physiology of voluntary muscle (British Medical Bulletin, 12, No. 3, 161 (1956). London: British Council. 15s. net). There are sixteen reviews in this symposium, and they succeed in giving a clear, connected and up-to-date summary of research in the physiology, biochemistry and biophysics of this type of muscle. The scientific editor is W. D. M. Paton, and the chairman of the planning committee is Sir Rudolph Peters, who contributes an introduction.

A. V. Hill contributes essays on thermodynamics and on the design of muscles. He mentions that an animal's muscles could be quickened about 20 per cent by raising its body temperature 2 deg. C., and he wonders whether, if this were achieved rapidly by diathermy, it would enable a good runner to do 100 yards in 8 seconds. He points out, though, that the margin of safety in mechanical strength of muscle systems is a small one and thinks that the experiment would be risky. There is an essay by A. F. Huxley, illustrated by photomicrographs, on the interpretation of muscle striations, based on work with modern techniques of light microscopy. This is followed by one on the 'ultra-structure' of muscle as revealed by the electron microscope and the X-ray camera $(H . \mathrm{H}$. Huxley). It is possible by means of suitable salt solutions to extract the main proteins of muscle selectively, so that the residual structure can be viewed after successive removal of myosin and actin. The results suggest a delightfully simple picture of muscle as being made up of discontinuous, parallel filaments of myosin and of actin which seem to slide or 'crawl' past one another during contraction, perhaps because of the pull exerted by oblique crosslinkages between the molecules of the two proteins. Adenosine triphosphate can affect this interaction
\end{abstract}

and may itself be brokèn down by myosin. The word 'crawl' would scarcely seem apt to $R$. G. Bannister, who contributes a section on muscle effort in running. In spite of the limits set by speed of muscle contraction or of oxygen supply, he believes that in a race, psychological factors-mental excitement and ability to ignore pain - "set the razor's edge between defeat and victory".

Mrs. D. M. Needham describes the biochemical reactions which provide energy for muscle con. traction. In the past, glycogen and creatine phosphate have successively been displaced from the role of primary energy source in muscle. Whether adenosine triphosphate will suffer the same fate remains to be seen, though there are hints of this in the work of H. A. Krebs and his colleagues and of W. F. H. M. Mommaerts (see Nature, 174,1081 ; 1954). At present, adenosine triphosphate seems to occupy the key position even after death, and E. C. Bate-Smith and J. R. Bendall show that the onset of rigor depends on the fall in the concentration, or in the turn-over rate, of this substance to a critical level. Other biochemical features of muscle are considered by K. Bailey and by S. V. Perry in their essays on the protein and enzyme systems of muscle.

The comparative physiology of muscle is discussed by C. F. A. Pantin and the methods of locomotion in fishes and four-footed animals by Sir James Gray. The role of the cell membrane is described by $B$. Katz, particularly the phenomenon of liberation of acetylcholine in quanta or 'pre-formed parcels' at the nerve-muscle junction. The only article of immediate clinical application is the one on familial periodic paralysis by B. McArdle, though Sir Rudolph Peters points out in his introduction that most of the academic research reviewed in the other essays is needed to provide a basis for complete understanding of this one disease.

Most of the reviews contain an up-to-date and fairly extensive bibliography, which greatly adds to their usefulness.
D. C. HaRrison

\section{SENSITIVITY OF IMMATURE MOUSE SPERM TO THE MUTAGENIC EFFECTS OF X-RAYS}

\author{
By DR. A. J. BATEMAN* \\ Cytogenetics Department, Christie Hospital and Holt Radium Institute, Manchester
}

\begin{abstract}
TN an earlier communication ${ }^{1}$, I questioned the 1 accepted view that the first three weeks mating of a male mouse irradiated with a dose in the neighbourhood of $500 \mathrm{r}$. represented all the post-meiotic stages of sperm at the time of irradiation ${ }^{2,3}$. My objection was based upon data being accumulated at the time and which can now be presented.

The mutagenic response was studied in terms of dominant lethals. Twelve days after their insemination, females were dissected and the numbers of corpora lutea, implantation sites and dead implants recorded. From this last category were excluded fotuses which had made appreciable growth before death. In so far as they are genetic in origin, these would arise

* British Empire Cancer Campaign Fellow.
\end{abstract}

from gene mutation rather than chromosome breakage and loss, which is the source of the main type of dominant lethal mutation.

It is usual (for example, Russell et $_{a l} .^{3}$ ) to estimate the proportion of dominant lethals from the corpora lutea not represented by live fotuses. This will include all dominant lethals; but unfortunately it will also include all unfertilized eggs. There is likely to be a substantial and erratic proportion of unfertilized eggs even in the control series (matings of unirradiated males), which is therefore an important source of random error. But if the treatment affects the amount of sperm, its fertilizing capacity, or even its ability having effected fertilization to promote cleavage, there is the possibility of a systematic error. 